\title{
Violência física ou sexual contra a mulher no Piauí, 2009-2016
}

\section{Physical or sexual violence against women in Piauí, 2009-2016}

\author{
Alberto Madeiro ${ }^{1}(\mathbb{D})$, Andréa Cronemberger Rufino ${ }^{1}$ (D) Ítalo Costa Sales ${ }^{2}$ (D) , Luma Carvalho e Queiroz ${ }^{2}$ (D) \\ 1. Docente do Curso de Medicina da Universidade Estadual do Piauí (UESPI), Teresina, PI, Brasil. 2. Discente do Curso de Medicina da Universidade Estadual \\ do Piauí (UESPI), Teresina, PI, Brasil.
}

\begin{abstract}
Resumo
Objetivo: descrever o perfil das notificações da violência física ou sexual contra mulheres de 10 a 49 anos no Piauí. Métodos: estudo descritivo e de série temporal, tendo como base os dados do Sistema de Informação de Agravos de Notificações entre 2009 e 2016. Análises bivariada e múltipla por regressão logística foram realizadas, com cálculo de odds ratio ajustadas (ORaj) e intervalos de confiança de 95\% (IC95\%). Resultados: houve notificação de 7.783 casos de violência contra mulheres de 10 a 49 anos, sendo 62,3\% de agressão física e 23,1\% de abuso sexual. Ocorreu maior chance de violência física entre mulheres com 20 anos ou mais (ORaj=1,68;IC95\% 1,49-2,07), casadas/ união estável (ORaj=2,18;IC95\% 1,98-2,32), praticada pelo parceiro íntimo (ORaj=2,20;IC95\% 1,44-2,97) e no ambiente doméstico (ORaj=2,22;IC95\% 1,55-3,41). Por sua vez, houve maior chance de violência sexual entre adolescentes de 10 a 19 anos (ORaj=1,78;IC95\% 1,44-2,19), solteiras (ORaj=1,94;IC95\% 1,33-2,51), perpetrada por desconhecidos (ORaj=1,88;IC95\% 1,30-2,84) e na via pública (ORaj=2,04;IC95\% 1,66-2,49). Conclusão: o perfil da violência física é diferente daquele da violência sexual, sendo a agressão física mais frequente entre mulheres casadas, no âmbito privado e por parceiro íntimo, enquanto o abuso sexual foi mais comum entre solteiras, praticado em local público e por desconhecidos. Os dados reforçam que o conhecimento desses perfis possibilita intervenções intersetoriais para prevenção e redução de danos da violência contra a mulher.
\end{abstract}

Palavras-chave: Violência contra a mulher. Violência por parceiro íntimo. Violência sexual. Sistemas de informação.

\begin{abstract}
Objective: to describe the profile of physical or sexual violence against women aged 10-49 in Piauí, Brazil. Methods: descriptive and time-series study based on data from the Notification of Injury Information System, 2009-2016. Bivariate and multiple logistic regression analyses were performed, with adjusted odds ratio calculation (ORaj) and $95 \%$ confidence intervals $(95 \% \mathrm{CI})$. Results: there were 7,783 reported cases of violence against women aged $10-49,62.3 \%$ of whom being physical aggression and $23.1 \%$ being sexual abuse. There was greater chance of physical violence among women aged 20 or older (ORadj=1.68;95\%CI 1.49-2.07), married/ stable union (ORadj=2.18;95\%CI 1.98-2.32), perpetrated by intimate partner (ORadj=2.20;95\%CI 1.442.97), and in the domestic environment (ORadj=2.22;95\%CI 1.55-3.41). In turn, there was greater chance of sexual violence among adolescents aged 1019 (ORadj=1.78;95\%CI 1.44-2.19), single (ORadj=1.94;95\%CI 1.33-2.51), committed by strangers (ORadj=1.88;95\%CI 1.30-2.84), and in the public place (ORadj=2.04;95\%CI 1.66-2.49). Conclusion: physical violence and sexual violence have different profiles, being physical aggression more frequent among married women, in private and by intimate partner, while sexual abuse was more common among single women, practiced in public place and by unknown persons. The data reinforce that the knowledge of these profiles can enable intersectoral interventions for preventing violence against women and reducing its harm.
\end{abstract}

Key words: Violence against women. Intimate partner violence. Sexual violence. Information systems.

\section{INTRODUÇÃO}

A violência contra as mulheres é um problema de saúde pública global. Apesar de ainda ocorrer subnotificação de casos, cerca de $35 \%$ das mulheres no mundo já sofreram alguma experiência de violência física e/ou sexual ao longo da vida, seja por parceiro íntimo, seja por desconhecido ${ }^{1,2} \mathrm{~A}$ maior parte dos casos, no entanto, é praticada no âmbito doméstico, e a estimativa é de que 1 em cada 3 mulheres com relacionamento afetivo já sofreu algum tipo de violência pelo parceiro ${ }^{2}$. No entanto, a prevalência varia entre as várias regiões do mundo, provavelmente influenciados por fatores socioculturais, comunitários, familiares ou individuais ou ainda dependendo da metodologia empregada para mensurar a violência. Dados da Organização Mundial de Saúde mostram variação da prevalência entre 23,2\% (países de alta renda) e 37\% (Sudeste Asiático) para a violência praticada por parceiro íntimo e entre 10,7\% (Américas) e 12,6\% (países de alta renda) para a violência praticada por estranhos, evidenciando que esse é um episódio comum na vida das mulheres ${ }^{3}$

Todas as mulheres podem ser acometidas pela violência. Crianças, adolescentes e adultas, independente de religião, condição social, cor da pele ou orientação sexual são atingidas por esse fenômeno, que pode determinar um amplo espectro de agravos em sua saúde física, mental, sexual e reprodutiva ${ }^{1,2,4}$.

Correspondente: Alberto Madeiro. Rua Olavo Bilac, 2335 - Teresina - Piauí - Brasil. CEP: 64049 550. E-mail: madeiro@uol.com.br

Conflito de interesse: Não há conflito de interesse por parte de qualquer um dos autores.

Recebido em: 21 Nov 2018; Revisado em: 6 Mar 2019; 26 Abr 2019; Aceito em: 29 Abr 2019 
Há maior chance de acometimento por HIV e outras doenças sexualmente transmissívei ${ }^{3-5}$, de gravidez indesejada e aborto induzido ${ }^{6}$, de abuso de álcool ${ }^{7}$, de depressão e suicídio, 8 além de lesões corporais e homicídios ${ }^{3,9}$. Por sua vez, quando a violência ocorre durante a gravidez, existe maior probabilidade de abortos espontâneos, partos prematuros, recém-nascidos com baixo peso ao nascer e baixas taxas de amamentação ${ }^{3,4,6}$.

A violência contra a mulher é multicausal, mas as normas hierárquicas de gênero e a crença da superioridade masculina sobre o corpo e o comportamento femininos exercem papel centra| ${ }^{10,11}$. Além de fatores socioculturais, há larga associação e superposição com determinantes comunitários, familiares e individuais. A faixa etária jovem, a raça negra, o baixo nível socioeconômico e a condição social desfavorável são encontrados com frequência, ainda que inconstantemente, entre mulheres com história de violência ao redor do mundo ${ }^{3,5-8,10}$. No Brasil, um inquérito populacional com mulheres de 15 a 49 anos de São Paulo e da Zona da Mata de Pernambuco que tiveram parceria afetivo-sexual com homens alguma vez na vida mostrou que os fatores de risco relacionados com violência por parceiro foram escolaridade até oito anos, violência física conjugal entre os pais da mulher, abuso sexual na infância, problemas com bebida alcoólica, além da autonomia financeira da mulher ${ }^{12}$.

Desde os anos 2000, a pauta da violência contra a mulher ganhou destaque no cenário público brasileiro. Em 2003, a Lei 10.778 regulamentou a obrigatoriedade de os profissionais notificarem os casos de violência contra a mulher atendidos nos serviços de saúde ${ }^{13}$ e, em 2006, o Ministério da Saúde implantou o Sistema de Vigilância de Violências e Acidentes (VIVA) nos serviços de referência de violências em todas as regiões ${ }^{14}$. No entanto, foi com a sanção da Lei 11.340 , conhecida como Lei Maria da Penha (LMP), também de 2006, que o Estado brasileiro respondeu às demandas das mulheres em situação de violência. Além de nominar essa situação como crime específico, a LMP estabeleceu a possibilidade de punições mais severas aos agressores e determinou medidas para proteção e prevenção da violência contra a mulher (como atendimento especializado em delegacias, campanhas educativas, medidas de assistência à mulher e protetivas contra o agressor) ${ }^{15}$.

Ainda que não se discuta a relevância da LMP, existem dúvidas sobre o seu impacto nas ocorrências não fatais e nos óbitos de mulheres submetidas à violência até o momento ${ }^{16}$. Mesmo que se considere que a subnotificação ainda é comum e que grande parte dos casos de violência não é captada pelos serviços de informação, o fato é que o número de denúncias feitas pelas mulheres cresce cada vez mais. Dados do Ligue 180, um serviço da Secretaria Especial de Políticas para as Mulheres que recebe denúncias de violência, demonstram que, a cada ano, as denúncias feitas pela própria mulher aumentam em média $52 \%^{17}$.

A realidade da violência contra a mulher no Piauí ainda é pouco conhecida. Há apenas dois estudos publicados, com dados sobre vítimas de violência atendidas em serviço de saúde especializado ${ }^{18,19}$. O presente estudo atualiza e amplifica os dados sobre violência para o Estado, tendo como foco a análise das características da violência física e sexual contra mulheres em idade reprodutiva no Piauí de 2009 a 2016.

\section{MÉTODOS}

Este é um estudo de série temporal, com dados das notificações de violência contra mulheres residentes no Piauí entre 2009 e 2016. O Piauí está localizado na região meio-norte do Nordeste brasileiro e conta com 224 municípios distribuídos em uma área de $251.611 \mathrm{~km}^{2}$. Em 2010, a população estimada foi de 3.204 .028 habitantes, dos quais $50,9 \%$ eram mulheres e, dessas, $63,8 \%$ estavam em idade reprodutiva ${ }^{20}$.

Esses dados foram coletados no VIVA, pertencentes ao Sistema de Informações de Agravos de Notificação (SINAN), por meio do programa Tabwin versão 3.6b. Somente os casos de violência física e sexual praticados por homens contra mulheres entre 10 e 49 anos foram incluídos, utilizando-se as definições de violência da Ficha de Notificação de Violência Doméstica, Sexual e/ou Outras Violências ${ }^{14}$ e da Organização Mundial de Saúde ${ }^{3}$. Violência física foi caracterizada como "ato violento com uso da força física intencional, não acidental, com o objetivo de ferir, lesar, provocar dor e sofrimento ou destruir a pessoa, deixando ou não marcas evidentes no corpo", ao passo que se aplicou o conceito de violência sexual para descrever qualquer "conduta que cause constrangimento em presenciar, manter ou a participar de relação sexual não desejada, mediante intimidação, ameaça, coação ou uso da força”, ${ }^{\prime 314}$. A faixa de 10 a 49 anos foi utilizada tendo como base a delimitação da OMS para idade reprodutiva ${ }^{3}$.

Foram avaliadas as variáveis disponíveis na Ficha de Notificação, como a) características da mulher: faixa etária (em anos: 10-14; 15-19; 20-29; 30-39; 40-49), cor da pele/raça (branca; preta; amarela; parda; indígena), escolaridade (sem escolaridade; da 1a à 8a série; ensino médio; ensino superior), situação conjugal (solteira; casada/união estável; separada; viúva); b) características do agressor: vínculo do agressor com a mulher (parceiro íntimo [cônjuge, ex-cônjuge, namorado, exnamorado], familiar [pai, padrasto, irmão, filho, cunhado, sogro], conhecido, desconhecido, outro); e c) características da agressão: ano de ocorrência (2009; 2010; 2011; 2012; 2013; 2014; 2015; 2016), local de ocorrência (residência; via pública; outro), número de agressores (um; dois ou mais) e tipo de violência (física; sexual).

Inicialmente, foram analisados os dados da violência contra todas as mulheres sob a forma de números absolutos e proporções. Para a violência física e sexual contra mulheres de 10 a 49 anos, consideraram-se apenas as variáveis cujos campos não estavam preenchidos como "ignorados/em branco" na análise inferencial. Análise bivariada foi realizada para identificar a associação entre variáveis independentes e violência física ou sexual, com utilização do teste do qui-quadrado (nível de significância de 20\%). Utilizou-se modelo de regressão logística 
para avaliar o efeito das variáveis independentes sobre a violência física e sexual. O critério para inclusão das variáveis foi a associação de $20 \%$ na análise univariada. Foram calculados odds ratios ajustados (ORaj) com os respectivos intervalos de confiança de 95\% (IC95\%), com nível de significância de 5\%. As categorias escolhidas como referência na análise ajustada foram aquelas consideradas como de menor frequência para a ocorrência de violência. As análises foram realizadas com o auxílio do software Stata ${ }^{\circledR}$, versão 12 .

Mesmo se tratando de dados secundários e de domínio público, o que dispensaria a revisão ética, a pesquisa foi aprovada por Comitê de Ética em Pesquisa da Universidade Estadual do Piauí (CAAE no 245606130.0.0000.5209).

\section{RESULTADOS}

Entre 2009 e 2016, foram registrados 10.167 casos de violência contra mulher de todas as idades no Piauí. Destes, 7.783 $(76,6 \%)$ foram entre mulheres de 10 a 49 anos. A agressão física $(62,3 \%)$ e a violência sexual $(23,1 \%)$ predominaram no período de vida reprodutivo das mulheres. A tabela 1 evidencia que as notificações de violência foram mais comuns entre mulheres de $20-29$ anos (35\%), com escolaridade entre a 1a e a 8 a série $(42,7 \%)$, pardas $(36,3 \%)$ e casadas ou em união estável $(41,2 \%)$. Parceiros íntimos foram responsáveis por 36,8\% das agressões, tendo a maior parte dos casos ocorrido na própria residência da mulher (63,5\%). Houve elevação progressiva das notificações de violência no período estudado, com pico dos registros em 2013 (2.322).

Tabela 1. Distribuição das ocorrências de violência contra mulheres de 10 a 49 anos, segundo características da vítima, vínculo com o agressor e características da violência. Piauí, 2009-2016.

\begin{tabular}{lrr}
\hline Característica & $\mathbf{n}$ & $\%$ \\
\hline Faixa etária (anos) & & \\
$10-14$ & 1.028 & 13,2 \\
$15-19$ & 1.190 & 15,3 \\
$20-29$ & 2.724 & 35,0 \\
$30-39$ & 1.970 & 25,3 \\
$40-49$ & 871 & 11,2 \\
Escolaridade & & \\
Sem escolaridade & 530 & 6,8 \\
1a a 8a série & 3.324 & 42,7 \\
Ensino médio & 1.961 & 25,2 \\
Ensino superior & 972 & 12,5 \\
Cor da pele/raça & & \\
Branca & & \\
Preta & 2.094 & 26,9 \\
Amarela & 630 & 8,1 \\
& 622 & 8,0 \\
\hline
\end{tabular}

\begin{tabular}{|c|c|c|}
\hline Característica & $\mathbf{n}$ & $\%$ \\
\hline Parda & 2.826 & 36,3 \\
\hline Indígena & 85 & 1,1 \\
\hline \multicolumn{3}{|l|}{ Situação conjugal ${ }^{3}$} \\
\hline Solteira & 2.281 & 29,3 \\
\hline Casada/união estável & 3.207 & 41,2 \\
\hline Separada & 552 & 7,1 \\
\hline Viúva & 155 & 2,0 \\
\hline Não se aplica & 677 & 8,7 \\
\hline \multicolumn{3}{|l|}{ Agente da agressão ${ }^{4}$} \\
\hline Parceiro íntimo & 2.865 & 36,8 \\
\hline Conhecido/amigo & 1.736 & 22,3 \\
\hline Desconhecido & 832 & 10,7 \\
\hline Familiar & 856 & 11,0 \\
\hline Outro & 1.105 & 14,2 \\
\hline \multicolumn{3}{|l|}{ Ano da ocorrência } \\
\hline 2009 & 223 & 2,9 \\
\hline 2010 & 250 & 3,2 \\
\hline 2011 & 406 & 5,2 \\
\hline 2012 & 656 & 8,4 \\
\hline 2013 & 2.322 & 29,8 \\
\hline 2014 & 979 & 12,6 \\
\hline 2015 & 1.226 & 15,8 \\
\hline 2016 & 1.721 & 22,1 \\
\hline \multicolumn{3}{|l|}{ Local de ocorrência } \\
\hline Residência & 4.943 & 63,5 \\
\hline Via pública & 1.229 & 15,8 \\
\hline Outro & 1.611 & 20,7 \\
\hline \multicolumn{3}{|l|}{ Número de agressores } \\
\hline Um & 6.499 & 83,5 \\
\hline Dois ou mais & 1.284 & 16,5 \\
\hline \multicolumn{3}{|l|}{ Natureza da violência } \\
\hline Física & 4.844 & 62,3 \\
\hline Sexual & 1.799 & 23,1 \\
\hline Outra $^{5}$ & 1.140 & 14,6 \\
\hline TOTAL & 7.783 & 100 \\
\hline
\end{tabular}

1. Faltam dados em 996 (12,8\%) casos; 2. Faltam dados em 1.526 $(19,6 \%)$ casos; 3. Faltam dados em 911 (11,7\%) casos; 4. Faltam dados em 389 (5,0\%) casos; 5 . Psicológica ( 970 casos; $12,5 \%$ ); negligência (103 casos; $1,3 \%$ ); econômica (41 casos; $0,5 \%$ ); tortura ( 26 casos; $0,3 \%$ ).

A tabela 2 mostra a violência física e sexual contra mulheres de 10 a 49 anos, segundo as variáveis analisadas. A violência física ocorreu mais comumente no ambiente doméstico (74\%), cometida por parceiros íntimos $(60,1 \%)$, com maior frequência entre mulheres de $20-29$ anos (39,3\%), pardas (50,7\%), casadas/ união estável $(58,2 \%)$ e com escolaridade da 1 a à 8 a série 
261 Violência contra a mulher no Piauí

(51,7\%). Já a violência sexual prevaleceu entre adolescentes de $10-19$ anos $(78,6 \%)$, solteiras $(49,6 \%)$, pardas $(52,8 \%)$, praticada por desconhecidos $(44,9 \%)$ na via pública $(60,1 \%)$ e com escolaridade entre 1 a à 8 a série $(52,8 \%)$. As variáveis que apresentaram associação ( $p<0,20)$ com violência física e sexual foram faixa etária, situação conjugal, escolaridade, agente da agressão e local da ocorrência.

Tabela 2. Associação entre violência física ou sexual contra mulheres de 10 a 49 anos, de acordo com as variáveis estudadas. Piauí, 2009-2016.

\begin{tabular}{|c|c|c|c|c|c|c|}
\hline \multirow{2}{*}{$\begin{array}{l}\text { Característica } \\
\text { Faixa etária }\end{array}$} & \multicolumn{3}{|l|}{ Violência física } & \multicolumn{3}{|c|}{ Violência sexual } \\
\hline & $\%$ & OR (IC95\%) & $\mathbf{p}$ & $\%$ & OR (IC95\%) & p \\
\hline $10-14$ & 5,2 & $0,65(0,18-1,98)$ & & 58,0 & $2,14(1,98-2,31)$ & \\
\hline $15-19$ & 13,9 & $1,15(1,04-1,28)$ & & 20,6 & $1,63(1,35-1,84)$ & \\
\hline $20-29$ & 39,3 & $1,56(1,38-1,92)$ & 0,024 & 12,0 & $1,33(1,20-1,56)$ & 0,018 \\
\hline $30-39$ & 28,9 & $1,34(1,15-1,58)$ & & 6,9 & $1,10(1,02-1,23)$ & \\
\hline $40-49$ & 12,7 & 1,00 & & 2,5 & 1,00 & \\
\hline \multicolumn{7}{|l|}{ Escolaridade } \\
\hline Sem escolaridade & 2,1 & $0,38(0,22-1,17)$ & \multirow{4}{*}{0,187} & 2,3 & $0,42(0,28-1,01)$ & \multirow{4}{*}{0,152} \\
\hline 1a a 8a série & 51,7 & $1,74(1,58-1,91)$ & & 52,8 & $1,77(1,50-1,96)$ & \\
\hline Ensino médio & 34,5 & $1,48(1,33-1,62)$ & & 34,9 & $1,42(1,30-1,58)$ & \\
\hline Ensino superior & 11,7 & 1,00 & & 10,0 & 1,00 & \\
\hline \multicolumn{7}{|l|}{ Cor da pele/raça } \\
\hline Branca & 24,3 & 1,00 & \multirow{5}{*}{0,246} & 25,3 & 1,00 & \multirow{5}{*}{0,288} \\
\hline Preta & 13,0 & $0,76(0,56-1,12)$ & & 12,3 & $0,70(0,53-1,23)$ & \\
\hline Amarela & 10,6 & $0,65(0,54-1,03)$ & & 8,7 & $0,52(0,38-1,03)$ & \\
\hline Parda & 50,7 & $1,42(1,33-1,57)$ & & 52,8 & $1,56(1,41-1,74)$ & \\
\hline Indígena & 1,4 & $0,43(0,28-1,00)$ & & 0,9 & $0,41(0,23-1,04)$ & \\
\hline \multicolumn{7}{|l|}{ Situação conjugal } \\
\hline Solteira & 16,1 & $1,41(1,23-1,89)$ & \multirow{4}{*}{0,042} & 49,6 & $1,64(1,45-1,88)$ & \multirow{4}{*}{0,033} \\
\hline Casada/união estável & 58,2 & $1,71(1,50-1,98)$ & & 15,8 & $1,43(1,12-1,68)$ & \\
\hline Separada & 6,2 & $1,21(0,94-1,45)$ & & 3,8 & $1,02(0,85-1,15)$ & \\
\hline Viúva & 3,0 & 1,00 & & 1,5 & 1,00 & \\
\hline \multicolumn{7}{|l|}{ Agente da agressão } \\
\hline Parceiro íntimo & 60,1 & $2,21(2,08-2,32)$ & \multirow{5}{*}{0,035} & 17,5 & $1,49(1,33-1,73)$ & \multirow{5}{*}{0,041} \\
\hline Conhecido/amigo & 21,6 & $1,54(1,39-1,73)$ & & 16,0 & $1,42(1,31-1,70)$ & \\
\hline Desconhecido & 6,6 & $1,09(0,95-1,33)$ & & 44,9 & $1,88(1,73-2,01)$ & \\
\hline Familiar & 8,8 & $1,18(0,87-1,27)$ & & 19,2 & $1,55(1,43-1,71)$ & \\
\hline Outro & 2,9 & 1,00 & & 2,4 & 1,00 & \\
\hline \multicolumn{7}{|l|}{ Número de agressores } \\
\hline Um & 96,5 & $2,12(1,99-2,43)$ & \multirow{2}{*}{0,301} & 89,9 & $1,87(1,70-2,03)$ & \multirow{2}{*}{0,365} \\
\hline Dois ou mais & 3,5 & 1,00 & & 10,1 & 1,00 & \\
\hline \multicolumn{7}{|l|}{ Local da ocorrência } \\
\hline Residência & 74,0 & $1,85(1,72-1,97)$ & & 20,5 & $1,02(0,93-1,95)$ & \\
\hline Via pública & 10,1 & $0,93(0,78-1,03)$ & 0,028 & 60,1 & $1,87(1,70-1,98)$ & 0,034 \\
\hline Outro & 15,9 & 1,00 & & 19,4 & 1,00 & \\
\hline
\end{tabular}

IC95\%: intervalo de confiança a 95\%; $p$ : teste do qui-quadrado $(p<0,20)$ 
Mulheres com 20 anos ou mais tiveram maior chance de violência física (ORaj=1,68;IC95\% 1,49-2,07), ao passo que aquelas menores de 20 anos tiveram mais probabilidade de violência sexual (ORaj=1,78;IC95\% 1,44-2,19). Houve maior propensão à violência física quando o agressor era o parceiro íntimo (ORaj=2,20;IC95\% 1,44-2,97) e a mulher estava casada ou em união estável (ORaj=2,18;IC95\% 1,98-2,32), e a injúria ocorreu na residência da mulher (ORaj=2,22;IC95\% 1,55-3,41). De forma diversa, houve maior chance de violência sexual em local público (ORaj=2,04;IC95\% 1,66-2,49), praticada por desconhecido (ORaj=1,88;IC95\% 1,30-2,84), sendo a vítima solteira (ORaj=1,94;IC95\% 1,33-2,51), como demonstra a tabela 3.

Tabela 3. Análise multivariada para associação entre tipo da violência e características da mulher, agente da agressão e local de ocorrência. Piauí, 2009-2016.

\begin{tabular}{ccc}
\hline Característica & Violência física & Violência sexual \\
\cline { 2 - 3 } & ORaj (IC95\%) & ORaj (IC95\%) \\
\hline
\end{tabular}

\begin{tabular}{|c|c|c|}
\hline \multicolumn{3}{|l|}{ Faixa etária (anos) } \\
\hline$<20$ & Ref. & $1,78(1,44-2,19)^{*}$ \\
\hline$\geq 20$ & $1,68(1,49-2,07)^{*}$ & Ref. \\
\hline \multicolumn{3}{|l|}{ Escolaridade } \\
\hline Até 8a série & $1,19(1,09-2,05)$ & $1,11(0,98-1,85)$ \\
\hline 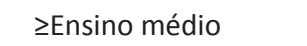 & Ref. & Ref. \\
\hline \multicolumn{3}{|l|}{ Situação conjugal } \\
\hline Solteira & $1,35(0,88-1,76)$ & $1,94(1,33-2,51)^{*}$ \\
\hline Casada/união estável & $2,18(1,98-2,32)^{*}$ & $1,20(0,74-2,19)$ \\
\hline Separada & $1,12(0,76-1,67)$ & $1,10(0,66-1,90)$ \\
\hline Viúva & Ref. & Ref. \\
\hline \multicolumn{3}{|l|}{ Agente da agressão } \\
\hline Parceiro íntimo & $2,20(1,44-2,97)^{*}$ & $1,35(0,72-2,81)$ \\
\hline Desconhecido & $1,05(0,71-2,03)$ & $1,88(1,30-2,84) *$ \\
\hline Familiar & $1,32(0,88-2,38)$ & $1,29(0,18-1,95)$ \\
\hline Conhecido/ amigo & Ref. & Ref. \\
\hline \multicolumn{3}{|l|}{ Local de ocorrência } \\
\hline Residência & $2,22(1,55-3,41)^{*}$ & $1,26(0,82-1,99)$ \\
\hline Via pública & $1,13(0,49-2,10)$ & $2,04(1,66-2,49)^{*}$ \\
\hline Bar & $1,01(0,37-2,42)$ & $0,95(0,17-1,45)$ \\
\hline Escola & Ref. & Ref. \\
\hline
\end{tabular}

ORaj (IC 95\%): odds ratio ajustado (intervalo de confiança 95\%); * $\mathrm{p}<$
0,05

\section{DISCUSSÃO}

Os dados do presente estudo evidenciam que as notificações de violência contra a mulher aumentaram de forma continuada no período avaliado. Além disso, o perfil da violência física foi diferente daquele encontrado na violência sexual. Enquanto a agressão física foi cometida, majoritariamente, em nível privado e por parceiro íntimo, o abuso sexual foi mais comumente praticado em local público e por desconhecidos. Ambos os tipos acometeram mulheres mais jovens (10-29 anos), mas mulheres casadas ou em união estável foram mais suscetíveis à violência física, e solteiras, à agressão sexual, semelhante ao observado em outros estudos nacionais ${ }^{12,21}$. Principalmente para a violência física, a hipótese é que a agressão inicie em idade mais precoce à medida que as mulheres envelhecem, elas ficam menos propensas à violência por se tornarem mais produtivas e independentes do ponto de vista econômico ${ }^{3,11,22}$.

É possível que o aumento dos registros no Piauí no período estudado decorra da obrigatoriedade das notificações, por profissionais de saúde, de todos os casos de violência doméstica e sexual ${ }^{13}$. Outro fator decisivo para esse incremento é a capacitação continuada dos profissionais de saúde, tanto para o atendimento adequado à vítima como para o esclarecimento sobre sua responsabilidade pela notificação. Por outro lado, há evidências de que o preenchimento da ficha de notificação ainda não está inserido rotineiramente nos serviços de saúde que atendem a vítimas de violência sexual ${ }^{23}$. Além dessa barreira, existe a possibilidade de que grande parte das ocorrências não ocasione atendimentos em saúde e, dessa forma, não tenha sido captada pelos sistemas de informação. Para 2014, por exemplo, a estimativa de subnotificação de estupros, no Brasil, foi de $35 \%^{24}$.

O predomínio de menor escolaridade nas mulheres vítimas de violência, encontrado no presente estudo, é um bem conhecido fator de risco para a violência por parceiro íntimo ${ }^{1,5-9,12}$. Mulheres em piores condições socioeconômicas, com sobreposição de vulnerabilidades, como menor renda e escolaridade mais baixa, apresentam maior probabilidade de vivenciar violência entre os pais e ter menos habilidades para identificar e barrar o comportamento violento do parceiro ${ }^{1,6,9,25}$. Em outros países, porém, a associação da escolaridade com a violência doméstica é inconsistente, com presunção de que seu efeito final na maior propensão à violência seja mediado por outras variáveis, como o elevado número de filhos, a união informal e o histórico de maus-tratos na família1,3,10.

Neste estudo, mulheres mais jovens tiveram mais possibilidade de sofrer violência física (20-29 anos) ou sexual (15-19 anos). Apesar de alguns estudos evidenciarem diminuição da prevalência da violência por parceiro íntimo a partir da quinta década de vida ${ }^{2,3,10}$ e maior frequência de violência sexual entre adolescentes $^{3,25}$, a idade não está associada com violência de forma inequívoca. ${ }^{1,3,12}$ A discrepância dos resultados pode se dever, em parte, à heterogeneidade metodológica dos levantamentos, dificultando a comparação. Muitos dados de pesquisas de base populacional brasileiras e mundiais mensuraram a ocorrência de violência ao longo da vida, 2,6-9,12 ao passo que outros estudos investigaram a violência no último $a_{n}{ }^{5}$, e outros, ainda, identificaram o episódio de violência que gerou necessidade de atendimento em saúde ${ }^{18,19,21}$. Esses últimos geralmente apresentam associação com faixa etária mais jovem, uma vez que a vulnerabilidade própria da idade para o enfrentamento da situação violenta pode levar mais frequentemente à busca por ajuda adequada. 
Os dados do presente trabalho sobre violência física são semelhantes àqueles de outros estudos, cuja principal face é a da agressão praticada por parceiro íntimo no ambiente doméstico ${ }^{1,3,12,21,25}$. Há consenso de que uma das principais explicações para esse fenômeno reside na crença tradicional de papéis específicos de gênero, com expectativa de que as mulheres demonstrem submissão ao parceiro e cuidem da casa e dos filhos, por exemplo ${ }^{10,11,22}$. A quebra desse paradigma, em muitas regiões do mundo, pode ter como consequência a violência física praticada pelo parceiro ou ex-parceiro ${ }^{1-3}$. Além de determinantes bem conhecidos, como baixa escolaridade, idade jovem e história de abuso na infância, existe forte associação de violência doméstica física com uso excessivo de álcool, tanto pela vítima, como pelo parceiro, ${ }^{2,10,12,21,25}$ um dado não mensurado por este estudo. Mulheres que informaram ter consumido álcool apresentam três vezes mais chance de sofrer algum tipo de violência física pelo parceiro e cinco vezes mais quando o parceiro consome álcool de forma abusiva ${ }^{3,7}$.

No Piauí, as ocorrências de violência sexual mais notificadas foram perpetradas por desconhecidos e em local público. No entanto, a literatura evidencia que grande proporção dos casos de estupro ocorre dentro de contexto conjugal íntimo, formal ou não ${ }^{1,12,18,23}$. É possível que, neste estudo, a subnotificação seja uma das explicações para a menor frequência de ocorrências de abuso sexual no ambiente doméstico e praticada por conhecidos da mulher, incluindo familiares. Comumente estigmatizada, a mulher vítima de violência sexual carrega sentimento de culpa e vergonha. Se, além disso, não há apoio da família, de amigos e mesmo dos serviços de saúde, pode ser difícil para ela compartilhar suas histórias, principalmente quando o agressor é alguém conhecido ou do círculo familiar íntimo 3,22,25.

A pequena proporção de casos notificados de abusos sexuais intrafamiliares observada neste estudo, provavelmente, espelha a marca da invisibilidade da violência sexual. Como vários estudos demonstram, os principais agressores são os próprios familiares, incluindo pais e padrastos, e conhecidos, quando as vítimas são crianças e adolescentes ${ }^{3,18,19}$. Muitas vezes, no entanto, o estupro perpetrado no ambiente doméstico apenas é revelado em caso de gravidez indesejada ${ }^{3,6}$. Um estudo censitário dos serviços de aborto legal no Brasil realizado entre 2013 e 2015 mostrou que 37\% das mulheres que interromperam a gravidez por estupro tinham menos de 19 anos (5 delas tinham menos de 10 anos quando abortaram), sendo razoável supor que grande parcela dessas violências tenha ocorrido no âmbito doméstico ${ }^{26}$.

O padrão, o grau e o efeito da violência sexual podem ser diferentes a depender do tipo e do número de agressores. Se, por um lado, a violência sexual por parceiro íntimo frequentemente acontece por longo prazo e com maiores sequelas psicológicas; por outro, o abuso sexual por estranhos tende a ser mais violento e com maior risco de lesões físicas associadas ${ }^{3,4,9,10,25}$. Apesar de a maioria dos estupros envolver apenas um agressor, os registros de estupros coletivos duplicaram entre 2011 e 2016 no país, ${ }^{27}$ com consequências mais graves para as mulheres, incluindo a possibilidade de morte. Em 2015, um estupro coletivo com grande repercussão midiática nacional ocorreu em Castelo do Piauí (PI), onde quatro adolescentes foram estupradas, agredidas fisicamente e atiradas de um penhasco por cinco homens (quatro menores de idade e um adulto), com morte de uma delas ${ }^{28}$.

Este estudo apresenta limitações que merecem ser consideradas. Primeiro, por se tratar de informações secundárias do inquérito VIVA, foram utilizadas apenas as variáveis do sistema coletadas durante o atendimento das mulheres em serviços de saúde, com ausência de dados que poderiam melhor esclarecer o fenômeno da violência, como o uso de álcool pela vítima ou o relato de violência prévia. Segundo, os resultados não podem ser generalizados para todas as mulheres que sofrem violência física e/ou sexual, uma vez que muitas não buscam atendimento em saúde e podem residir em localidades ainda não cobertas pelo VIVA. Terceiro, tendo em vista o foco do estudo entre mulheres em idade reprodutiva, não foram analisados os dados de crianças (abaixo de 10 anos) e de mulheres acima de 50 anos, apesar da elevada frequência de violência nessas faixas etárias. Por outro lado, merece destaque o fato de que este é o primeiro relato, com abrangência estadual, da violência sofrida por mulheres de 10 a 49 anos no Piauí, reforçando a magnitude e as lacunas do problema e indicando, ao mesmo tempo, a necessidade de novos estudos, principalmente aqueles de base populacional.

Apesar dos avanços com a Lei Maria da Penha, a violência contra a mulher é um crime frequentemente invisível, seja pelo silêncio de muitas mulheres, seja pela escassez de delegacias especializadas ou, ainda, pela subnotificação dos profissionais de saúde, os casos registrados representam apenas uma parcela dos eventos. Como exemplo, no Piauí, entre 2009 e 2016, apenas 133 dos 227 municípios (58,6\%) notificaram ao SINAN atendimentos de mulheres vítimas de violência ${ }^{29}$. Além disso, o estado conta com delegacias especializadas para atendimento à mulher em somente sete cidades, sugerindo a presença de obstáculos geográficos para o registro da queixa ${ }^{30}$. Dessa forma, mesmo diante da magnitude dos dados realçados por este trabalho, torna-se evidente que os sistemas de informação devem ser aperfeiçoados, alargando a cobertura e melhorando a qualidade dos dados coletados.

\section{REFERÊNCIAS}

1. Devries KM, Mak JYT, García-Moreno C, Petzold M, Child JC, Falder G, Lim S, Bacchus LJ, Engell RE, Rosenfeld L, Pallito C, Vos T, Abrahams N, Watts CH. The global prevalence of intimate partner violence against women. Science. 2013 Jun; 340(6140):1527-8. doi: http://dx.doi.org/10.1126/science.1240937.

2. García-Moreno C, Jansen HA, Ellsberg M, Heise L, Watts CH; WHO Multi- country Study on Women's Health and Domestic Violence against Women Team. Prevalence of intimate partner violence: findings from the WHO multicountry study on women's health and domestic violence. Lancet. 2006 Oct; 368(9543): 1260-9. doi: 10.1016/S0140-6736(06)69523-8

3. World Health Organization. Global and regional estimates of violence against 
women: prevalence and health effects of intimate partner violence and nonpartner sexual violence. Geneve: WHO; 2013.

4. Campbell J. Health consequences of intimate partner violence. Lancet. 2002 359(9314): 1331-6. doi: 10.1016/S0140-6736(02)08336-8.

5. Jewkes RK, Dunkle K, Nduna M, Shai N. Intimate partner violence, relationship power inequity, and incidence of HIV infection in young women in South Africa: a cohort study. Lancet. 2010 Jul; 376(9734):41-8. doi: https://doi.org/10.1016/ S0140-6736(10)60548-X.

6. Pallitto CC, García-Moreno C, Jansen HAFM, Heise L, Ellsberg M, Watts C WHO Multi-country Study on Women's Health and Domestic Violence. Intimate partner violence, abortion, and unintended pregnancy: results from the WHO Multi-country Study on Women's Health and Domestic Violence. Int J Gynecol Obstet. 2013 Jan; 120(1):3-9. doi: 10.1016/j.ijgo.2012.07.003.

7. Devries KM, Child JC, Bacchus LJ, Mak J, Falder G, Graham K, Watts C, Heise L. Intimate partner violence victimization and alcohol consumption in women: a systematic review and meta-analysis. Addiction. 2014 Mar; 109(3):379-91. doi: 10.1111/add.12393.

8. Devries KM, Mak JY, Bacchus LJ, Child JC, Falder G, Petzold M, Watts C. Intimate partner violence and incident depressive symptoms and suicide attempts: a systematic review of longitudinal studies. PLoS Med. 2013;10(5): e1001439. doi: 10.1371/journal.pmed.1001439.

9. Stöckl H, Devries K, Rotstein A, Abrahams N, Campbell J, Watts C, García-Moreno. The global prevalence of intimate partner homicide: a systematic review. Lancet. 2013 Sep; 382(9895):859-65. doi: 10.1016/S0140$6736(13) 61030-2$

10. Krug EG, Dahlberg LL, Mercy JA, Zwi AB, Lozano R. World report on violence and health. Geneva: WHO; 2002.

11. Schraiber LB, d'Oliveira AFPL, Couto MT. Violência e saúde: contribuições teóricas, metodológicas e éticas de estudos da violência contra a mulher. Cad Saude Publica. 2009; 25(sup. 2):S205-16. doi: http://dx.doi.org/10.1590/S0102$311 \times 2009001400003$.

12. d'Oliveira AFPL, Schraiber LB, França-Junior I, Ludermir AB, Portella AP, Diniz $\mathrm{CS}$, Couto MT, Valença $\mathrm{O}$. Fatores associados à violência por parceiro íntimo em mulheres brasileiras. Rev Saude Publica. 2009 Apr; 43(2):299-310. doi: http:// dx.doi.org/10.1590/S0034-89102009005000013.

13. Brasil. Lei no 10.778 , de 24 de novembro de 2003. Estabelece a notificação compulsória, no território nacional, do caso de violência contra a mulher que for atendida em serviços públicos ou privados. Diário Oficial da República Federativa do Brasil. 2003 Nov 25; Seção 1.

14. Ministério da Saúde (BR). Secretaria de Vigilância em Saúde. Departamento de Análise de Situação de Saúde. VIVA: instrutivo de notificação de violência doméstica, sexual e outras violências. Brasília: Ministério da Saúde; 2011.

15. Brasil. Lei no 11.340, de 7 de agosto de 2007. Cria mecanismos para coibir a violência doméstica e familiar contra a mulher, nos termos do inciso 80 do artigo 226 da Constituição Federal, da Convenção sobre a Eliminação de Todas as Formas de Discriminação contra as Mulheres e da Convenção Interamericana para Prevenir, Punir e Erradicar a Violência contra a Mulher; altera o Código de Processo Penal, o Código Penal e Lei de Execução Penal; e dá outras providências. Diário Oficial da União. 2006 Ago 8; Seção 1.

16. Garcia LP, Freitas LRS, Höfelmann DA. Avaliação do impacto da Lei Maria da Penha sobre a mortalidade de mulheres por agressões no Brasil, 2001-2011. Epidemiol Serv Saude. 2013; 22(3):383-94. doi: http://dx.doi.org/10.5123/ S1679-49742013000300003.

\section{Como citar este artigo/How to cite this article:}

17. Secretaria Especial de Política para as Mulheres. Ligue 180 - Central de Atendimento à Mulher. Relatório 2017 [internet]. [acesso 2018 Out 22]. Disponível em: https://www.mdh.gov.br/informacao-ao-cidadao/ouvidoria/ RelatrioGeral2017.pdf.

18. Lopes IMRS, Gomes KRO, Silva BB, Deus MCBR, Galvão ERCG, Borba DC. Caracterização da violência sexual em mulheres atendidas no projeto MariaMaria em Teresina-PI. Rev Bras Ginecol Obstet. 2004;26(2):111-6. doi: http:// dx.doi.org/10.1590/S0100-72032004000200005.

19. Monteiro FFS, Teles DCBS, Castro KL, Vasconcelos NSV, Magalhães RLB, Deus MCBR. Violência sexual contra criança no meio intrafamiliar atendidos no SAMVVIS, Teresina, PI. Rev Bras Enferm. 2008; 61(4):459-63. doi: http://dx.doi. org/10.1590/S0034-71672008000400010.

20. Instituto Brasileiro de Geografia e Estatística. Estados: Piauí: censo 2010 [Internet]. Rio de Janeiro: IBGE; 2017 [acesso 2018 Out 28]. Disponível em: http://www.ibge.gov.br/estadosat/perfil.php?sigla=pi.

21. Garcia LP, Duarte EC, Freitas LRS, Silva GDM. Violência doméstica e familiar contra a mulher: estudo de casos e controles com vítimas atendidas em serviços de urgência e emergência. Cad Saude Publica. 2016; 32(4):e00011415. doi: http://dx.doi.org/10.1590/0102-311X00011415.

22. Bandeira LM. Violência de gênero: a construção de um campo teórico e de investigação. Soc Estado. 2014;29(2):449-69. doi: http://dx.doi.org/10.1590/ S0102-69922014000200008.

23. Sousa MH, Bento SF, Osis MJD, Ribeiro MP, Faúndes A. Preenchimento da notificação compulsória em serviços de saúde que atendem mulheres que sofrem violência sexual. Rev Bras Epidemiol. 2015 Jan-Mar; 18(1):94-107. doi: 10.1590/1980-5497201500010008.

24. Fórum Brasileiro de Segurança Pública. Anuário Brasileiro de Segurança Pública 2015 [internet]. Segurança Pública em números. Estatísticas criminais. São Paulo: Fórum Brasileiro de Segurança Pública; 2015 [acesso 2018 Out 29]. Disponível em: http://www.forumseguranca.org.br/storage/9_anuario_2015. retificado_.pdf.

25. Guedes A, Bott S, García-Moreno C, Colombini M. Bridging the gaps: a global review of intersections of violence against women and violence against children. Glob Health Action. 2016;9:31516. doi: 10.3402/gha.v9.31516.

26. Madeiro AP, Diniz D. Serviços de aborto legal no Brasil - um estudo nacional. Cienc Saude Coletiva. 2016;21(2):563-72. doi: 10.1590/141381232015212.10352015.

27. Colucci C. País registra 10 estupros coletivos por dia; notificações dobram em 5 anos. Folha de São Paulo [internet]; 2017 [acesso 2018 Out 30]. Disponível em: http://www1.folha.uol.com.br/cotidiano/2017/08/1911346-pais-registra10-estupros-coletivos-por-dia-notificacoes-dobram-em-5-anos.shtml.

28. Frazão F. Estupro, espancamento e morte: a tarde de horror no Piauí. Veja. com [internet]; 2015 [acesso 2018 Out 30]. Disponível em: https://veja.abril. com.br/brasil/estupro-espancamento-e-morte-a-tarde-de-horror-no-piaui/.

29. Departamento de Informática do SUS. Informações de Saúde. Violência doméstica, sexual e/ou outras violências - Piauí [internet]. Brasília: Ministério da Saúde; 2017 [acesso 2018 Out 30]. Disponível em: http://tabnet.datasus.gov. $\mathrm{br} / \mathrm{cgi} /$ deftohtm.exe?sinannet/cnv/violepi.def.

30. Piauí. Polícia Civil. Unidades policiais [internet]. Teresina: Governo do Estado do Piauí; 2017 [acesso 2018 Out 30]. Disponível em: http://www.pc.pi.gov.br/ unidades.php.

Madeiro A, Rufino AC, Sales IC, Queiroz LC. Violência física ou sexual contra a mulher no Piauí, 2009-2016. J Health Biol Sci. 2019 Jul-Set; 7 (3):258-264. 